\title{
Glucose tolerance in siblings of Type 1 diabetic patients: relationship to HLA status
}

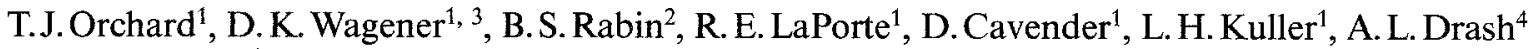 \\ and D.J.Becker ${ }^{4}$ \\ ${ }^{1}$ Department of Epidemiology, Graduate School of Public Health, and ${ }^{2}$ Department of Pathology, School of Medicine, University of Pittsburgh, \\ ${ }^{3}$ Department of Psychiatry, Western Psychiatric Institute Clinic, \\ ${ }^{4}$ Division of Endocrinology, Department of Pediatrics, Children's Hospital of Pittsburgh, Pittsburgh, Pennsylvania, USA
}

\begin{abstract}
Summary. In this report, we present an analysis of glucose and insulin responses during oral glucose tolerance tests in 369 siblings of Type 1 diabetic patients. All have been HLA typed at the A, B and C loci. Though most had normal glucose tolerance by National Diabetes Data Group criteria ( $92 \%$ of the males and $95 \%$ of the females), siblings who shared both HLA haplotypes with the diabetic patient in the family had higher mean 3-hour glucose areas than those who shared one or neither HLA haplotype $(p<0.01)$. This difference was more marked in males and older siblings. Insulin concentrations did not differ significantly between the two groups except that, for those aged < 16 years, the group sharing both haplotypes had lower fasting insulin concentrations $(p=0.05)$; for 16-29 year olds, the corresponding group had marginally higher 3 -hour insulin areas than the remainder of
\end{abstract}

siblings $(p=0.17)$. Little association with specific haplotypes $\left(A_{1} B_{8}\right.$ or $\left.A_{2} B_{15}\right)$ was seen. Multivariate analyses, adjusting for age and obesity, eliminated the 3 -h glucose difference in females by HLA sharing status $(p=0.37)$ although in males it remained significant $(p<0.001)$. Failure to account for age, sex and obesity may explain some of the conflicts in the reported literature. The glucose tolerance differences seen by HLA haplotype sharing status did not correlate with the presence of anti-islet cell antibodies. These results are consistent with the hypothesis that the HLA identical siblings, particularly males, have different (i.e. worse) glucose tolerance than their haploidentical and non-HLA identical siblings.

Key words: Type 1 diabetes - Genetics - Aetiology - Glucose tolerance - HLA type - Islet cell.
Consistent with their known increased risk of developing Type 1 diabetes mellitus, siblings of Type 1 diabetic patients have been thought to have a higher frequency of glucose tolerance abnormalities than the general population [1-3]. The risk for developing Type 1 diabetes, which we estimate from our registry to be approximately $3.5 \%$ [4], is further increased for siblings who share both HLA haplotypes with the diabetic patient [5].

Recently, therefore, interest has focused on whether a sibling's HLA sharing status with the diabetic patient in the family, or his or her possession of specific HLA antigens, is itself associated with glucose tolerance and/ or insulin secretory abnormalities. Thus far, published data have been conflicting. One recent study reported an exaggerated insulin response [6] while another suggested a lower insulin response in HLA identical siblings [7]. Indeed, different patterns of abnormalities were also seen when we initially looked at our own data three years ago compared to our findings one year later on a larger sample [8]. In this report, we present data on 369 siblings in order to test the hypothesis that those sib- lings with the greater risk of developing Type 1 diabetes (i.e. the HLA identical) will more frequently demonstrate abnormalities of glucose tolerance and insulin concentrations and/or, as a group, show differences in glucose tolerance when compared to siblings who share only 1 or 0 HLA haplotypes, consistent with their greater risk $[5,9]$. Furthermore, we also examine whether those that share two haplotypes, which include $B_{8}$ and $B_{15}$, show even greater glucose tolerance abnormalities. These analyses take into account the marked effect of age, sex and obesity on glucose tolerance and insulin concentration which we have previously described in this population [10]. Failure to account for these influences on glucose tolerance is likely to be partly responsible for the conflicting data published to date. We also examine whether siblings with anti-islet cell antibodies (ICA) show worse glucose tolerance than those without, since such antibodies, which are thought to be indicative of B cell destruction, have been reported to be associated with both abnormal intravenous glucose responses and the subsequent development of Type 1 diabetes [11]. 


\section{Subjects and methods}

The subjects are full siblings of Type 1 diabetic patients seen as part of a large epidemiologic/family study of Type 1 diabetes and were not previously known to have diabetes [12]. Briefly, families of new cases of Type 1 diabetes presented to Children's Hospital of Pittsburgh (CHP) since February 1979, were eligible for the study. This report focuses on the 93 families seen up to January 1982, who represent over $95 \%$ of all eligible families. The siblings in these families have undergone a 4-h oral glucose tolerance test (GTT) using $1.75 \mathrm{~g}$ of glucose/ $\mathrm{kg}$ body weight, maximum dose $100 \mathrm{~g}$. Further details are published elsewhere [10]. Viral and immunologic studies, including HLA typing at the $\mathrm{A}, \mathrm{B}$ and $\mathrm{C}$ loci and anti-islet cell antibody determinations (ICA), were also performed. A further series of 80 families of children diagnosed prior to 1979, who form a comparison study of single and multiple case families, have also had 4-h GTT and HLA typing. The siblings from these families are also included in this report. Thus we have a study population comprising 369 full siblings (all aged less than 30 years: 189 males, mean age 15.3 and 180 females, mean age 15.3 years) of Type 1 diabetic patients. The total number available for any particular glucose, insulin, HLA or anti-islet cell antibody determination is usually somewhat less than this figure because of technical difficulties (insufficient plasma, etc.). This, in particular, applies to the analyses based on HLA haplotype sharing status with the diabetic sibling patient, for this is not always determinable without the HLA type of parents (not always available for testing), or because of the presence of blanks or possible homozygous status in parents. In addition, sera from only 256 siblings were available from the time of glucose tolerance for ICA testing.

Haplotype sharing status of siblings was determined by comparing the segregation of haplotypes in the siblings with the first diagnosed (or only) diabetic sibling patient in that family.

HLA typing was performed using the standard Amos procedure [13] and trays bought from the University of California Board of Reagents (UCLA, Los Angeles, CA, USA). Plasma glucose was measured by the glucose oxidase method using a YSI analyser, while plasma insulin was measured by radioimmunoassay [14]. Anti-islet cell antibody determinations were performed by a new immunohistochemical technique [15] which has been validated against the immunofluorescent assay [16].

The statistical approach has been to compare differences in glucose and insulin measures (fasting and 3-h area) and the ratio of the 15 min: peak insulin measures between siblings of different HLA types or sharing status. To avoid the potential problem of multiple comparisons, analyses were limited to these five overall measures. However, in order to examine for confounding, and for age or sex specific influences, analyses were repeated after stratification by age and sex. The Mann-Whitney $U$ test was chosen because the basic hypothesis is that, within certain subgroups of siblings, there will be a greater number who will be at the end of the distribution for various glucose or insulin measures. Consequently, a rank sum test is appropriate. Furthermore, parametric tests would be inappropriate for the glucose and insulin values, particularly the latter, which were not normally distributed and could not be normalized by transformation.

Standardized residuals were similarly analysed, following regression of of age and Body Mass Index (BMI) on the glucose and insulin values, to examine whether any HLA differences are truly independent of age and BMI differences. In order to do this, we first pooled all of the siblings of the same sex under age 30 years. A regression was then calculated separately for glucose and insulin values (dependent variables) using age, age squared and BMI as independent variables. The square of age was used because previous analysis by stratification [10] indicated that the relationship between these measures and age was nonlinear. The residuals were calculated as the difference between the observed value for an individual and the expected value for that individual based on the appropriate regression equation. The percentage of variance explained by the regressions ranged from 12 to $50 \%$.

\section{Results}

Table 1 shows the results of the glucose tolerance tests of the siblings by age and sex classified according to the National Diabetes Data Group (NDDG) criteria [17]. It can be seen that none had diabetes, and that few fulfilled the criteria of impaired glucose tolerance. We have chosen the age of 16 years as the dividing line between the childhood and adult criteria given by this committee.

Table 2 shows the fasting and 3-h areas under the curves, for plasma glucose and insulin concentrations, by the presence or absence of the specific HLA haplotypes $A_{1} B_{8}$ or $A_{2} B_{15}$ and by the number of haplotypes shared (either 2 ( $\mathrm{SH} 2)$ or 0 and 1 combined $\left(\mathrm{SH}_{01}\right)$ ) with the diabetic patient in the family. Since there were no

Table 1. Glucose tolerance test results of siblings by age, sex and National Diabetes Data Group criteria

\begin{tabular}{|c|c|c|c|c|c|c|}
\hline \multirow{2}{*}{$\begin{array}{l}\text { GTT } \\
\text { category }\end{array}$} & \multicolumn{3}{|c|}{ Males } & \multicolumn{3}{|c|}{ Females } \\
\hline & $\begin{array}{l}<16 \\
\text { years }\end{array}$ & $\begin{array}{l}16-29 \\
\text { years }\end{array}$ & All ages & $\begin{array}{l}<16 \\
\text { years }\end{array}$ & $\begin{array}{l}16-29 \\
\text { years }\end{array}$ & All ages \\
\hline Normal & 80 & 81 & $161(92 \%)$ & 81 & 79 & $160(97 \%)$ \\
\hline Abnormal & 10 & 7 & $7 \quad(4 \%)$ & 0 & 4 & $4 \quad(2 \%)$ \\
\hline Impaired & 5 & 2 & $7 \quad(4 \%)$ & 1 & 0 & $1 \quad(1 \%)$ \\
\hline Total & 85 & 90 & $175(100 \%)$ & 82 & 83 & $165(100 \%)$ \\
\hline
\end{tabular}

Table 2. Plasma glucose and insulin measures (fasting ' 0 ' $\mathrm{min}$ and 3-h area under the curve) by haplotype and by haplotype sharing status

\begin{tabular}{|c|c|c|c|c|c|c|}
\hline HLA status & & $n^{\mathrm{b}}$ & $\begin{array}{l}' 0 \text { ' min glucose } \\
\mathrm{mmol} / \mathrm{1}\end{array}$ & $\begin{array}{l}\text { 3-h glucose area } \\
\mathrm{mmol} \cdot 1^{-3} \cdot \mathrm{min}^{-1}\end{array}$ & $\begin{array}{l}' 0 \text { ' min insulin } \\
\mathrm{mU} / 1\end{array}$ & $\begin{array}{l}\text { 3-h insulin area } \\
\mathrm{mU} \cdot 1^{-3} \cdot \mathrm{min}^{-1}\end{array}$ \\
\hline$A_{1} B_{8}$ & $\begin{array}{l}+ \\
-\end{array}$ & $\begin{array}{r}81 \\
288\end{array}$ & $\begin{array}{l}4.8 \pm 0.4 \\
4.8 \pm 0.4\end{array}$ & $\begin{array}{l}4.3 \pm 2.6 \\
4.6 \pm 2.6\end{array}$ & $\begin{array}{l}9.3 \pm 4.8 \\
9.5 \pm 6.1\end{array}$ & $\begin{array}{l}107.0 \pm 54.7 \\
110.5 \pm 61.2\end{array}$ \\
\hline $\mathrm{A}_{2} \mathrm{~B}_{15}$ & $\begin{array}{l}+ \\
-\end{array}$ & $\begin{array}{r}34 \\
335\end{array}$ & $\begin{array}{l}4.9 \pm 0.4 \\
4.8 \pm 0.4\end{array}$ & $\begin{array}{l}4.3 \pm 2.3 \\
4.6 \pm 2.6\end{array}$ & $\begin{array}{l}9.5 \pm 4.5 \\
9.4 \pm 6.0\end{array}$ & $\begin{array}{l}100.8 \pm 46.3 \\
110.7 \pm 61.0\end{array}$ \\
\hline $\begin{array}{l}\text { Number of shared } \\
\text { haplotypes }\end{array}$ & $\begin{array}{l}2 \\
0 \\
1 \\
0,1\end{array}$ & $\begin{array}{r}70 \\
74 \\
157 \\
231\end{array}$ & $\begin{array}{l}4.8 \pm 0.5 \\
4.8 \pm 0.4 \\
4.8 \pm 0.4 \\
4.8 \pm 0.4\end{array}$ & $\begin{array}{l}5.3 \pm 2.9^{\mathrm{a}} \\
4.4 \pm 2.0 \\
4.3 \pm 2.6 \\
4.3 \pm 2.4^{\mathrm{a}}\end{array}$ & $\begin{array}{l}8.8 \pm 5.6 \\
9.3 \pm 5.6 \\
9.7 \pm 6.2 \\
9.6 \pm 6.0\end{array}$ & $\begin{array}{l}116.8 \pm 76.0 \\
102.2 \pm 49.9 \\
100.4 \pm 55.9 \\
105.1 \pm 53.9\end{array}$ \\
\hline
\end{tabular}

Results expressed as mean \pm SD. ${ }^{a} p<0.01$ (3-h glucose area $\mathrm{S}_{2} \vee \mathrm{S}_{01}$; ${ }^{\mathrm{b}}$ The number of individuals given is for fasting glucose values; the number available for the other measures may be slightly lower due to missed or insufficient samples 

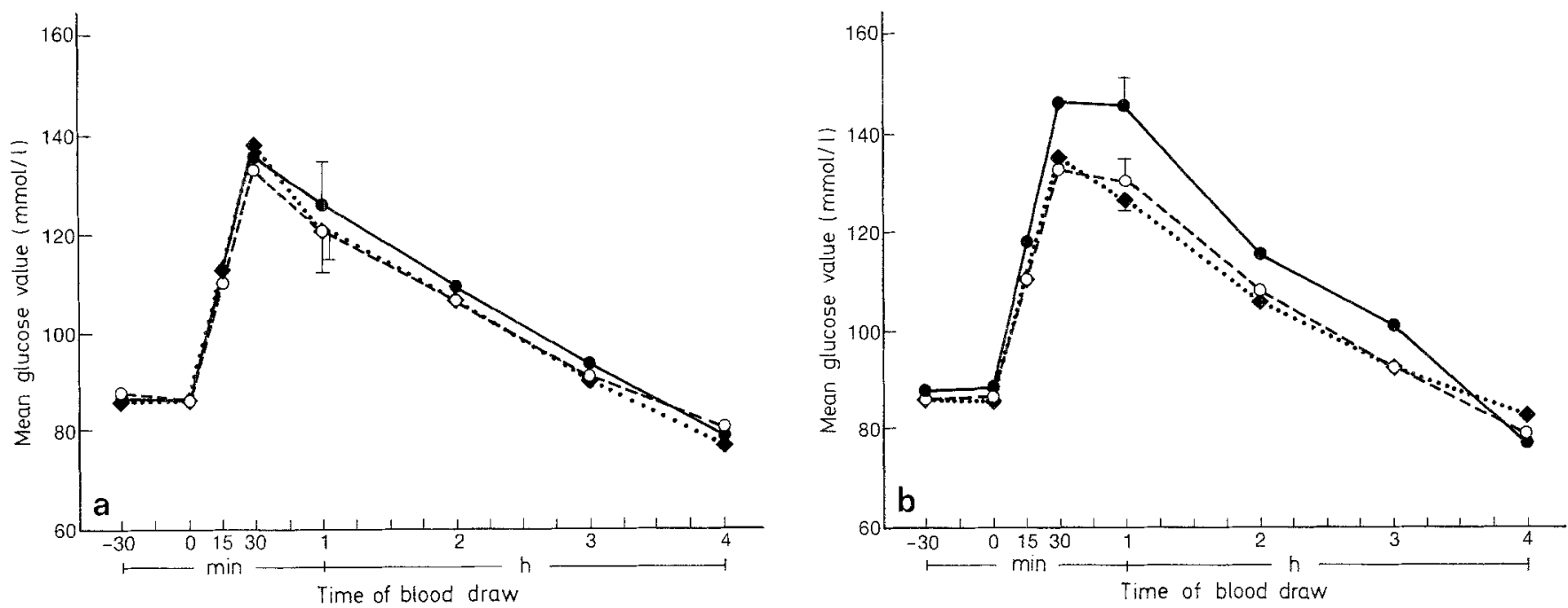

Fig. 1. a Mean glucose concentrations (mmol/1) of siblings aged under 16 years according to HLA sharing status with the diabetic indexed patient. (SEM bar at 1-h). $\triangle-\cdots \triangle$ Share 0 Haplotypes $(n=36) ; \times \cdots \times$ share 1 haplotype $(n=82)$; $\square-\square$ share 2 haplotypes $(n=33)$. Glucose challenge $=1.75 \mathrm{~g}$ of glucose per $\mathrm{kg}$ body weight (maximum dose $100 \mathrm{~g}$ ). b Mean glucose concentrations (mmol/1) of siblings aged 16-29 according to HLA sharing status with the diabetic indexed patient. (SEM bar at 1-h). $\Delta----\Delta$ share 0 haplotypes $(n=29) ; \times----\times$ share 1 haplotype $(n=74)$; $\square \longrightarrow \square$ share 2 haplotype $(n=37)$. Glucose challenge $=1.75 \mathrm{~g}$ of glucose per $\mathrm{kg}$ body weight (maximum dose $100 \mathrm{~g})$
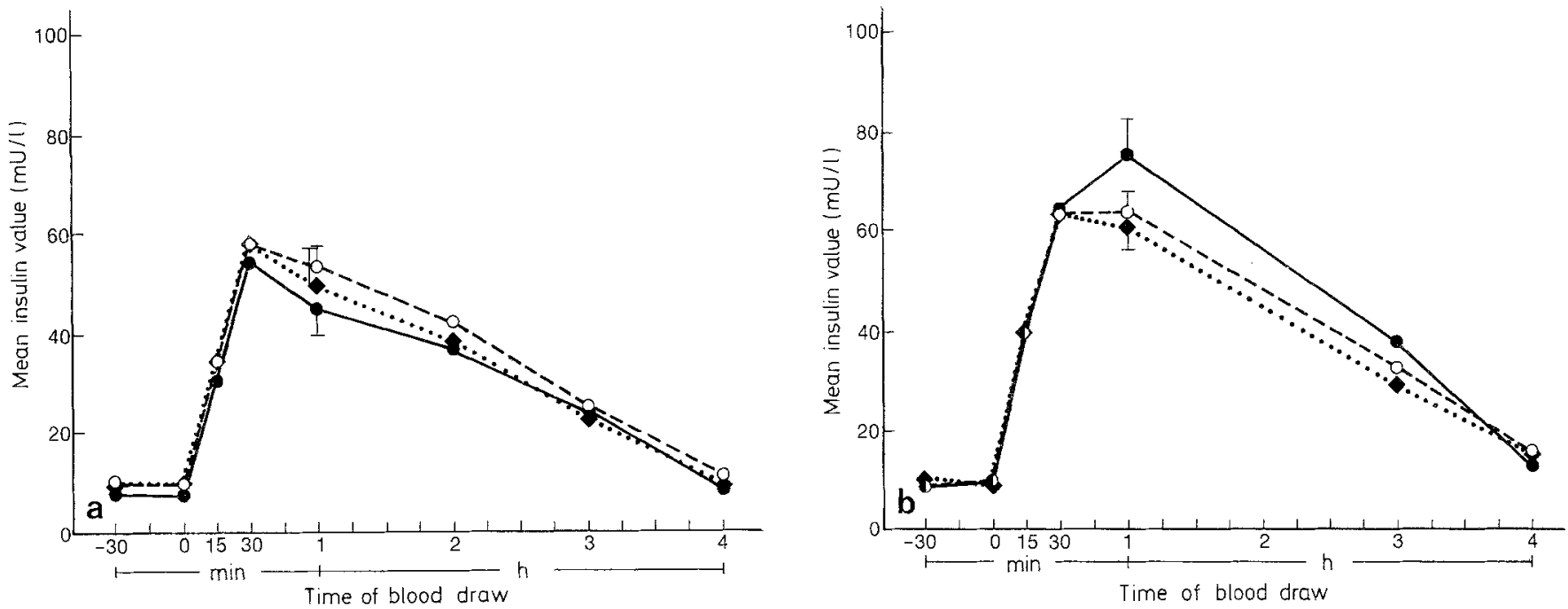

Fig. 2. Mean insulin concentrations (mU/1) of siblings aged under 16 years according to HLA sharing status with the diabetic indexed patient. (SEM bar at 1 -h). $\triangle---\triangle$ share 0 haplotypes $(n=36) ; \times---\times$ share 1 haplotype $(n=82) ; \square-\square$ share 2 haplotypes ( $n=33$ ). Glucose challenge $=1.75 \mathrm{~g}$ of glucose per $\mathrm{kg}$ body weight (maximum dose $100 \mathrm{~g}$ ). b Mean insulin concentrations (mU/1) of siblings aged 16-29 according to HLA sharing status with the diabetic indexed patient. (SEM bar at 1-h). $\triangle \cdots-\cdots$ Share 0 Haplotypes $(n=39) ; \times-\cdots \times$ share 1 haplotype $(n=74)$; $\square-\square$ share 2 haplotypes $(n=37)$. Glucose challenge $=1.75 \mathrm{~g}$ of glucose per kg body weight (maximum dose $100 \mathrm{~g}$ )

differences between siblings sharing 0 and 1 haplotypes (Table 2 and Figures 1-2), these groups have been combined for analyses. Fifteen min: peak insulin ratio was depressed in $\mathrm{SH}_{2}$ compared to $\mathrm{SH}_{01}$ (0.49 vs. 0.57 , $p=0.03$ ). The only other significant difference is the higher 3 -h glucose area in the share 2 haplotype group compared to the share 0 or 1 haplotype group $(p<0.01)$. When these data were age, BMI and sex corrected, the residual 3 -h glucose areas still differed significantly $(p=0.01)$. The next step was to determine if there was a particular subgroup of these siblings who largely accounted for the significant difference.
Age specific analyses.

These age specific analyses are shown in Figures $1 \mathrm{a}$ and $1 \mathrm{~b}$ (glucose) and $2 \mathrm{a}$ and $2 \mathrm{~b}$ (insulin) with the sample sizes as shown. Although the 3 -h glucose area was higher overall for the share 2 haplotype group, neither this $(p<0.29)$ nor the fasting glucose $(p=0.83)$ differed significantly from the share 0,1 group (Fig. 1 a) for those aged less than 16 years. Examination of similar data for the 16-29 year old group, however, revealed a significantly higher 3 -h glucose area $(p<0.01)$ for the share 
Table 3. Glucose and insulin measures (fasting ' 0 ' min and 3-h area under the curve) by haplotype, haplotype sharing status and sex of siblings

\begin{tabular}{|c|c|c|c|c|c|c|c|c|c|c|c|}
\hline \multirow[t]{2}{*}{ Haplotype group } & & \multicolumn{4}{|c|}{$\begin{array}{l}{ }^{\prime} 0 \text { ' min glucose } \\
\mathrm{mmol} / \mathrm{l}\end{array}$} & \multicolumn{2}{|c|}{$\begin{array}{l}\text { 3-h glucose area } \\
\mathrm{mmol} \cdot \mathrm{1}^{-3} \cdot \mathrm{min}^{-1}\end{array}$} & \multicolumn{2}{|c|}{$\begin{array}{l}' 0 \text { ' min insulin } \\
\mathrm{mU} / 1\end{array}$} & \multicolumn{2}{|c|}{$\begin{array}{l}\text { 3- } \mathrm{h} \text { insulin area } \\
\mathrm{mU} \cdot 1^{-3} \cdot \mathrm{min}^{-1}\end{array}$} \\
\hline & & $\mathrm{n}$ & Male & $\mathrm{n}$ & Female & Male & Female & Male & Female & Male & Female \\
\hline$A_{1} B_{8}$ & $\begin{array}{l}+ \\
-\end{array}$ & $\begin{array}{r}38 \\
151\end{array}$ & $\begin{array}{l}4.9 \pm 0.4 \\
4.9 \pm 0.4\end{array}$ & $\begin{array}{r}43 \\
137\end{array}$ & $\begin{array}{l}4.6 \pm 0.4 \\
4.7 \pm 0.5\end{array}$ & $\begin{array}{l}4.8 \pm 2.8 \\
4.9 \pm 2.4\end{array}$ & $\begin{array}{l}3.9 \pm 2.5 \\
4.3 \pm 2.7\end{array}$ & $\begin{array}{l}9.9 \pm 4.9^{\mathrm{a}} \\
8.3 \pm 0.6^{\mathrm{a}}\end{array}$ & $\begin{array}{r}8.7 \pm 4.6^{\mathrm{c}} \\
10.7 \pm 6.4^{\mathrm{c}}\end{array}$ & $\begin{array}{l}113.8 \pm 63.5 \\
103.4 \pm 52.0\end{array}$ & $\begin{array}{l}101.3 \pm 46.3 \\
118.1 \pm 69.2\end{array}$ \\
\hline $\mathrm{A}_{2} \mathrm{~B}_{15}$ & $\begin{array}{l}+ \\
-\end{array}$ & $\begin{array}{r}16 \\
173\end{array}$ & $\begin{array}{l}5.0 \pm 0.4 \\
4.9 \pm 0.4\end{array}$ & $\begin{array}{r}18 \\
162\end{array}$ & $\begin{array}{l}4.7 \pm 0.3 \\
4.7 \pm 0.5\end{array}$ & $\begin{array}{l}4.8 \pm 2.8 \\
4.9 \pm 2.4\end{array}$ & $\begin{array}{l}3.9 \pm 1.7 \\
4.2 \pm 2.8\end{array}$ & $\begin{array}{l}9.5 \pm 4.7 \\
8.5 \pm 5.6\end{array}$ & $\begin{array}{r}9.5 \pm 4.5 \\
10.3 \pm 6.2\end{array}$ & $\begin{array}{l}103.7 \pm 42.6 \\
105.6 \pm 55.6\end{array}$ & $\begin{array}{r}98.1 \pm 50.4 \\
116.0 \pm 66.0\end{array}$ \\
\hline $\begin{array}{l}\text { Number of shared } \\
\text { haplotypes }\end{array}$ & $\begin{array}{l}2 \\
0.1\end{array}$ & $\begin{array}{r}43 \\
125\end{array}$ & $\begin{array}{l}4.9 \pm 0.3 \\
4.9 \pm 0.4\end{array}$ & $\begin{array}{r}30 \\
117\end{array}$ & $\begin{array}{l}4.8 \pm 0.7 \\
4.7 \pm 0.4\end{array}$ & $\begin{array}{l}5.5 \pm 2.4^{\mathrm{b}} \\
4.5 \pm 2.4^{\mathrm{b}}\end{array}$ & $\begin{array}{l}5.1 \pm 3.6 \\
4.1 \pm 2.4\end{array}$ & $\begin{array}{l}8.2 \pm 5.0 \\
8.7 \pm 5.9\end{array}$ & $\begin{array}{r}9.7 \pm 6.4 \\
10.4 \pm 6.1\end{array}$ & $\begin{array}{r}113.9 \pm 55.9 \\
96.8 \pm 48.0\end{array}$ & $\begin{array}{l}126.1 \pm 98.7 \\
113.7 \pm 58.5\end{array}$ \\
\hline
\end{tabular}

Results expressed as mean $\pm \mathrm{SD}$. ${ }^{\mathrm{a}} p=0.03\left(\mathrm{~A}_{1} \mathrm{~B}_{8}+\mathrm{v}\right.$ - $/$ males. ${ }^{\prime} 0$ ' min insulin; ${ }^{\mathrm{b}} p=0.01\left(\mathrm{~S}_{2} \mathrm{v} \mathrm{S}_{01} / \mathrm{males}\right) .3-\mathrm{h}$ glucose area; ${ }^{\mathrm{c}} p=0.09\left(\mathrm{~A}_{1} \mathrm{~B}_{8}+\mathrm{v}\right.$ /females). ' 0 ' min insulin

2 group though, again, the fasting glucose differences were not significantly different $(p=0.39)$ (Fig. 1b).

The plasma insulin responses showed contrasting, but not significant, age related patterns. In the less than 16 year olds, the share 2 group showed marginally lower fasting insulin concentrations $(p=0.05)$ but similar 3-h areas ( $p=0.69$ ), while for the 16-29 year olds, the share 2 group had similar fasting concentrations $(p=0.92)$ but marginally higher 3 -h insulin areas $(p=0.17)$. The 15 min: peak insulin ratio did not differ in either age group by sharing status.

\section{Sex specific analyses}

Analysing the data by sex (Table 3 ) revealed, in males, a significantly higher $3-\mathrm{h}$ glucose area for those sharing 2 haplotypes compared to those sharing 0 or 1 haplotype $(p=0.01)$. Neither fasting insulin nor the 3-h insulin area differed significantly according to sharing status in the males. Though possession of HLA haplotype $\mathrm{A}_{2} \mathrm{~B}_{15}$ was not associated in males with any differences in glucose tolerance, siblings with $\operatorname{HLA~A}_{1} \mathrm{~B}_{8}$ had significantly higher fasting insulin concentrations $(p=0.03)$.

Even though the absolute difference in the mean concentrations of the 3-h glucose area was of a similar magnitude by haplotype sharing status for both sexes, in the females the significance was only $p=0.21$, reflecting the greater variance in females who share 2 haplotypes. In contrast to the males, females who possessed the $A_{1} B_{8}$ haplotype showed a lower fasting insulin concentration. However, the statistical significance of this was only $p=0.09$ despite the absolute difference in the means being greater than seen in the males. Again, the variance in the group of females was greater than in the corresponding group of males (Table 3). The 15 min: peak insulin ratio did not differ by sharing status in either sex.

When the 3-h glucose areas were adjusted for age and BMI, the marginal significance of the female data for sharing 2 versus sharing 0 or 1 completely disappeared $(p=0.37)$. However, the males still showed a clear difference between those brothers who shared two haplotypes compared to those who shared 0 or 1 haplo- type $(p=.001)$. After age and BMI adjustment of the insulin values (both fasting and 3 -h areas), no significant differences were seen by HLA sahring status.

\section{Combination of HLA risk factors}

There were three siblings who would be considered to have the greatest risk of developing Type 1 diabetes, i. e. who were HLA identical and possessed both $B_{8}$ and $\mathrm{B}_{15}$. These three siblings (all aged less than 16 years, 2 girls and 1 boy) had a high mean 3 -h glucose area of $7.1 \mathrm{mmol} \cdot 1^{-3} \cdot \mathrm{min}^{-1}$ with one of them developing Type 1 diabetes 17 months later [18]. As indicated above, the presence or absence of HLA $\mathrm{A}_{1} \mathrm{~B}_{8}$ or $\mathrm{A}_{2} \mathrm{~B}_{15}$ alone did not seem to be associated with greater glucose intolerance.

The above results indicate that the 3-h glucose area in siblings who share 2 haplotypes with the proband may be higher than that of other siblings although the overlap between these two subpopulations is great. The data was also analysed categorically (i.e. according to NDDG criteria) by sharing status. The frequency of abnormal or impaired tests was greater for the $S_{2}(8.5 \%)$ than for the $\mathrm{S}_{01}(4.2 \%)$ groups, though this did not reach significance.

\section{Family-based analyses}

It may be argued that since some siblings came from the same families, they did not represent independent observations. In order to address this potential problem, the analyses were repeated on a subgroup comprising one sibling from each family. This subgroup was formed by first choosing an HLA identical sibling from each family with such an individual (randomly when two such siblings were available), and then randomly selecting one sibling from the remaining families. All selections were done without knowledge of the glucose tolerance results. These analyses largely confirmed the above findings. For example, the mean 3-h glucose area of the share 2 group was $5.4 \mathrm{mmol} \cdot \mathrm{l}^{-3} \cdot \mathrm{min}^{-1} \mathrm{com}$ pared to $4.2 \mathrm{mmol} \cdot 1^{-3} \cdot \mathrm{min}^{-1}$ for those sharing 0 or 1 haplotype $(p=0.136)$. Thus, though the absolute difference between these subgroups is marginally greater 
(i. e. $0.1 \mathrm{mmol} \cdot 1^{-1} \cdot \mathrm{min}^{-1}$ ) than was the case for all siblings, the difference was less significant, probably reflecting the smaller sample size (154 versus 301$)$. As before, little difference was seen in mean 3 -h glucose areas for those aged less than 16 years $\left(4.4 \mathrm{vs} .4 .1 \mathrm{mmol} \cdot 1^{-3}\right.$ $\left.\cdot \min ^{-1}, p=0.52\right)$, while a larger difference was seen for those aged $16+$ years $\left(6.4\right.$ vs. $4.5 \mathrm{mmol} \cdot 1^{-3} \cdot \mathrm{min}^{-1}$, $p=0.076$ ). Sex-specific analyses revealed a higher mean 3-h glucose area in both sexes for the share 2 group, although, as before, the significance was greater for the males $(p=0.06)$ than the females $(p=0.18)$. As with the total population, the statistical significance of resulting age and BMI adjusted 3-h glucose areas was greater by HLA sharing status for males $(p=0.17)$ than for females $(p=0.40)$, though neither were significant. As this probably reflects the small number of siblings in the familybased data set, it underscores the subtlety of these findings and the need for large sample sizes to adequately examine these differences.

\section{Anti-islet cell antibody data}

Ten out of 256 siblings tested (4\%) had anti-islet cell antibodies (ICA). Eight were boys and six were aged less than 16 years. These ten individuals showed very similar glucose tolerance to those without ICA (none had a 3-h glucose area more than 1SD above the mean of the HLA $_{01}$ group). One had a 3-h insulin area greater than $1 \mathrm{SD}$ above the $\mathrm{S}_{01}$ group mean; however, this 10-yearold girl showed a double hump GTT curve with glucose peaks of $8.2 \mathrm{mmol} / 1$ and $7.8 \mathrm{mmol} / 1$ at $15 \mathrm{~min}$ and $1 \mathrm{~h}$ respectively. Though two subjects had low $15 \mathrm{~min}$ insulin (and $15 \mathrm{~min}$ : peak insulin ratio), this was thought to reflect delayed glucose absorption rather than impaired first-phase insulin response since in neither case was the 15-min glucose value increased over fasting by more than $15 \%$. Two ICA positive siblings have recently had intravenous GTT tests; one was normal while the other had marked loss of first-phase insulin. This HLA identical twin of a Type 1 diabetic patient proband is now aged 33. He has had impaired glucose tolerance (with low 15-min insulin) for the last 4 years though his initial OGTT, included in this data set, was normal.

Thus, the exclusion from the analyses of these 10 ICA positive subjects had no effect on the previous findings (e.g., 3-h glucose area for $S_{2} \vee S_{01}$ was 5.5 vs. $4.4 \mathrm{mmol} \cdot 1^{-3} \cdot \min ^{-1}, p=0.03$ ). These results suggest, therefore, that the HLA related differences noted above are independent of ICA evidence of B cell destruction. The distribution of HLA sharing status of these 10 siblings was: $S_{2}-3, S_{1}-5, S_{0}-2$. Their HLA antigens were: $\mathrm{B}_{27} \mathrm{~B}_{17}, \quad \mathrm{~B}_{8} \mathrm{~B}_{8}, \quad \mathrm{~B}_{8} \mathrm{~B}_{18}, \quad \mathrm{~B}_{18} \mathrm{~B}_{12}, \mathrm{~B}_{15} \mathrm{~B}_{40}, \mathrm{~B}_{35} \mathrm{~B}_{17}, \mathrm{~B}_{40} \mathrm{~B}_{40}$, $\mathrm{B}_{44} \mathrm{~B}_{44}, \mathrm{~B}_{17} \mathrm{~B}_{13}, \mathrm{~B}_{8} \mathrm{~B}_{27}$.

\section{Discussion}

In this report, we have demonstrated that when age, sex and obesity (as measured by body mass index) are taken into account, siblings of Type 1 diabetic patients who share two haplotypes with their diabetic sibling show a greater disturbance of glucose tolerance during oral GTT than those who share 0 or 1 haplotypes. This effect appears to be limited to the male siblings as evidenced by the multivariate analyses. However, gross abnormalities of glucose tolerance were uncommon in this population and we were unable to demonstrate significant glucose intolerance in siblings aged $<16$ years according to HLA haplotype sharing status. Furthermore, the possession of those haplotypes associated with Type 1 diabetic patients $\left(A_{1} B_{8}, A_{2} B_{15}\right)$ by the siblings does not, of itself, appear to be of much importance in discriminating variations of glucose tolerance.

These results, therefore, are constistent with our previously reported data delineating the risks of developing Type 1 diabetes [19, 20], and they emphasize that the predominant feature is whether or not one shares both haplotypes with the diabetic patient and not the specific antigen that a sibling possesses. This is consistent with the notion that a gene important to the determination of glucose metabolic abnormalities is linked to the B-locus, but that the locus itself (or the antigens themselves) is not necessarily involved. HLA DR typing is not, unfortunately, available for this data set. The demonstration that differences in glucose tolerance become manifest in the older age group, i. e. particularly in men aged 16 to 29 years, is a fascinating and puzzling finding. It raises the possibility that certain individuals, in our case identified by their HLA sharing status with a diabetic patient sibling, have an inborn deterioration of B cell function which may become manifest in terms of disturbed glucose tolerance with increasing age and consequent exposure to immunologic, physiologic and other stresses. At younger ages, this defect would presumably only become manifest by the development of frank diabetes after a severe insult. The greater variance of $3-h$ glucose area in the females sharing both haplotypes could also reflect a more heterogenous response to the stress of the menstrual cycle in these particular girls. Unfortunately, we were unable to obtain good data on the menstrual status of these subjects.

The failure to show any association between antiislet cell antibody status and glucose tolerance may partially relate to the low frequency $(4 \%)$ of such antibodies in siblings of cases and, therefore, small sample size $(n=10)$. The Joslin group have shown a strong association between ICA and both loss of the first-phase insulin response to intravenous glucose and subsequent Type 1 diabetes in monozygotic twins and triplets [11, 21]. However, our failure, and that of the New York group [7], to show an association between ICA and glucose tolerance does throw some doubt on the predictive value of ICA in these more general sibling populations. This is particularly true in the light of a report from a study similar to ours (Barts-Windsor-Middlesex) suggesting that ICA may, in some cases, be transient and unrelated to subsequent Type 1 diabetes [22]. However, 
methodological problems in terms of sensitivity may be related to the issue of transient ICA antibodies [23].

Though the work of Rosenbloom suggests that oral glucose tolerance tests are predictive of subsequent Type 1 diabetes as much as seven years before diagnosis [24], oral glucose may not allow as fine an examination of insulin secretory dynamics as intravenous glucose. Thus, it remains possible that even our ten siblings with ICA may have shown loss of the first-phase insulin after intravenous glucose. Nonetheless, it is clear from our data that, independent of ICA associated glucose tolerance abnormalities, older siblings sharing two haplotypes with their diabetic sibling show worse glucose tolerance than other nondiabetic siblings. This suggests that such siblings may have an underlying defect of glucose tolerance, which may predispose them to diabetes even though the majority will not develop Type 1 diabetes [20].

The literature concerning HLA sharing status and glucose tolerance is conflicting. A recent report [7] reveals a much greater degree of glucose abnormality amongst the share 2 status group than we demonstrate and lower, rather than our marginally higher, insulin concentrations. One probable reason for this difference is that they have a high proportion of males in their share 2 group compared to the other two groups, and, as we have previously shown, male relatives of Type 1 diabetic patients demonstrate higher glucose values and lower insulin values than females [10].

Whether relatives of Type 1 diabetic patients (and, in particular, HLA identical siblings) show increased or decreased insulin concentrations also remains controversial. As indicated, our data suggest only a marginal increase in insulin concentration during oral glucose tolerance tests and little consistent evidence for delayed production as measured by the 15-min: peak insulin ratio. Decreased early phase insulin release in response to intravenous glucose in relatives of patients with diabetes has been well documented in the literature. This occurs in the face of normal glucose disappearance rates $[25,26]$. Similar findings have been found with oral glucose [27]. During oral glucose tolerance testing in some abnormal states, the insulin response to glucose may be delayed in timing, even though values reached may be normal or higher than normal [27-29]. This delayed insulin release is reflected by a low $15 \mathrm{~min}$ and often $30 \mathrm{~min}$ insulin level. The 15 -min value reflects early phase insulin release after oral glucose and is stimulated by gut factors as well as ambient blood sugar levels.

We found no difference in the 15 -min values between the different groups. However, because the rate of insulin response at 15 min may be sluggish compared to the final peak produced, a ratio between this $15 \mathrm{~min}$ value and the peak was analysed in order to give a numerical value to this abnormal situation in order that it could be statistically analysed. The data from the Joslin Clinic [21] showing decreased first-phase insulin re- sponse to intravenous glucose is accompanied by failure of early insulin responses to oral glucose when a 15 -min value is available. Thus, in that data set, changes in insulin response to intravenous glucose appear to be accompanied by decreases in early responses to oral glucose. Though lower overall for share 2 siblings, this ratio did not differ significantly in the age or sex subgroups.

One group has reported decreased insulin concentrations which we suspect partially reflect, as indicated above, an uneven sex distribution [7]; others report elevated insulin concentrations both for first degree relatives [30] and HLA identical siblings [31, 32] of Type 1 diabetic patients during oral glucose tolerance tests. It is unlikely that these different results are fully explained by the difficulties encountered with oral glucose tolerance tests, for example, gut factors and dynamics of the blood sugar rise, since similar divergent results are reported for intravenous arginine/glucose tolerance tests. Hollander [6] reported exaggerated acute phase insulin secretion in HLA identical siblings while Srikanta [11, 21] reported progressive loss of first-phase insulin response to intravenous glucose before hyperglycaemia became detectable in initially discordant monozygotic twins. These conflicts, and our failure to show insulin differences despite glucose differences, may well reflect the difficulty of assessing insulin activity by peripheral (as opposed to portal) sampling in the absence of concurrent measures of counter regulatory hormones and receptor activity, as well as the different methodologies used in the various studies.

A further reason for these contradictory reports probably results form the underlying heterogeneity of Type 1 diabetes risks and aetiology. For example, the less marked abnormalities amongst our siblings compared to other reports, and the lower rate of conversion (i.e. siblings who develop diabetes after the index case in the family) in the Pittsburgh population [4] compared to New York [7] and Barts-Windsor [33], could reflect such a heterogeneity in environmental and/or host risk characteristics.

Acknowledgements. The authors would like to acknowledge the technical assistance of M. Banks, K. Eckenrode and J.Martell and the cooperation of all the families involved. The study was funded in part by NIH grants AM24021, AM00885 and MH00299.

\section{References}

1. Gottlieb MS (1980) Diabetes in offspring and siblings of juvenileand-maturity onset-type-diabetes. Diabetes 33: 331-339

2. Burkeholder JN, Pickens JM, Womack WN (1967) Oral glucose tolerance test in siblings of children with diabetes mellitus. Diabetes $16: 156-160$

3. Pyke DA, Cassar J, Todd J, Taylor KW (1970) Glucose tolerance and serum insulin in identical twins of diabetics. Br Med $\mathrm{J}$ 12: 649-651

4. Wagener DK, Kuller LH, Orchard TJ, LaPorte RE, Rabin B, Drash AL (1982) Pittsburgh diabetes mellitus study. II: Secondary 
attack rates in families with insulin-dependent diabetes mellitus. Am J Epidemiol 115: 868-878

5. Cavender DE, Wagener DK, Orchard TJ, LaPorte RE, Becker DJ, Kuller LH (1984) Multivariate analyses of the risk of insulin-dependent diabetes mellitus for siblings of insulin-dependent diabetic patients. Am J Epidemiol 120(2): 315-327

6. Hollander PH, Asplin CM, Kniaz D, Hansen JA, Palmer JP (1982) Beta-cell dysfunction in nondiabetic HLA identical siblings of insulin-dependent diabetics. Diabetes 31:149-153

7. Ginsberg-Fellner F, Dobersen MJ, Witt ME, Rayfield EJ, Rubinstein P, Notkins AL (1982) HLA antigens, cytoplasmic islet cell antibodies, and carbohydrate tolerance in families of children with insulin-dependent diabetes mellitus. Diabetes 31:292-298

8. Orchard TJ, Becker DJ, Rabin B (1981) Pathogenesis of insulin diabetes mellitus: A function of sample size? Diabetes 30 (Suppl 1): 559 (Abstract)

9. Christy M, Green A, Christau B, Kromann H, Nerup J, Platz P, Thomsen M, Tyder LP, Svejgaard A (1979) Studies of the HLA system and insulindependent diabetes mellitus. Diabetes Care 2: 209-214

10. Orchard TJ, Becker DJ, Kuller LH, Drash AL, Banks M (1982) Age and sex variations in glucose tolerance and insulin responses: parallels with cardiovascular risks. J Chron Dis 35: 123-132

11. Srikanta S, Ganda OP, Eisenbarth GS, Soeldner JS (1983) Isletcell antibodies and beta-cell function in monozygotic triplets and twins initially doscordant for Type 1 diabetes mellitus. N Engl $\mathbf{J}$ Med 308: 322-325

12. Drash $\mathrm{AL}$, LaPorte RE, Kuller LH, Wagener DK, Orachrd TJ, Fishbein HA, Becker DJ, Rabin B (1981) The descriptive epidemiology of insulin-dependent diabetes mellitus (IDDM) in Allegheny County, PA. In: Martin JM, Ehrlich RM, Holland FJ (eds) Etiology and pathogenesis of insulin-dependent diabetes mellitus, Raven Press, New York, pp 211-226

13. Amos B (1974) Manual of tissue typing techniques. (DHEW Publication No.77-545) National Institutes of Health, Washington, DC, pp 23-26

14. Herbert V, Lau KS, Gottlieb CW (1965) Coated charcoal immunoassay of insulin. J Clin Endocrinol Metab 25: 1375-1384

15. Krell J, Rabin BS (1984) Comparison of an immunohistochemical and immunofluorescence procedure to detect antibody to pancreatic islet cells. Diabetes 33: 709-711

16. Cavender D, Rabin B, Finegold D (1984) A new sensitive immunohistochemical assay for islet cell cytoplasmic antibodies (ICA). Diabetes 33 (Suppl 1): 250 (Abstract)

17. National Diabetes Data Group (1979) Classification and diagnosis of diabetes mellitus and other categories of glucose intolerance. Diabetes 23: 1039-1057

18. Orchard TJ, Backer DJ, Atchison RW, LaPorte RE, Wagener DK, Rabin BS, Kuller LH, Drash AL (1983) The development of Type 1 (insulin-dependent) diabetes mellitus: Two contrasting presentations. Diabetologia 25: 89-92

19. Cavender DE, Wagener DK, Rabin BS, Becker DJ, Orchard TJ, Eberhardt MS, LaPorte RE, Drash AL, Kuller LH (1984) The Pittsburgh insulin-dependent diabetes mellitus (IDDM) study. HLA antigens and haplotypes as risk factors for the development of IDDM in IDDM patients and their siblings. J Chron Dis 37 (7): pp 555-568
20. Cavender DE, Wagener DK, Orchard TJ, LaPorte RE, Becker DJ, Kuller LH (1984) Multivariate analyses of the risk of insulin-dependent diabetes mellitus for siblings of insulin-dependent diabetic patients. Am J Epidemiol 120(2):315-327

21. Srikanta S, Ganda OP, Jackson RA, Gleason RE, Kaldany A, Garovoy MR, Milford EL, Carpenter CB, Soeldner JS, Eisenbarth GS (1983) Type 1 diabetes mellitus in monozygotic twins: chronic progressive beta cell dysfunction. Ann Intern Med 99 (3):320-326

22. Spencer KM, Dean BM, Tarn A, Lister J, Bottazzo GF (1984) Fluctuating islet-cell autoimmunity in unaffected relatives of patients with insulindependent diabetes. Lancet 764-766

23. Srikanta S, Eisenbarth GS (1984) Disappearing anti-islet antibodies? Lancet 1176-1177 (Letter)

24. Rosenbloom AL, Hunt SS, Rosenbloom EK, MacLaren NK (1982) Ten-year prognosis of impaired glucose tolerance in siblings of patients with insulin-dependent diabetes. Diabetes 31: 385-387

25. Cerasi E, Luft R (1967) "What is inherited - What is added" Hypothesis for the pathogenesis of diabetes mellitus. Diabetes 16 : 615-621

26. Simpson RG, Benedetti A, Grodsky GM, Karam JH, Forsham PH (1968) Early phase of insulin release. Diabetes 17:684-692

27. Colwell J, Lein A (1967) Diminished insulin response to hyperglycemia in pre-diabetes and diabetes. Diabetes 16:560-568

28. Berson SA, Yalow RS (1965) Some current controversies in diabetes research. Diabetes 14: 549-572

29. Seltzer HS, Allen EW, Herron AL, Brennan MT (1967) Insulin secretion in response to glycemic stimulus: Relation of delayed initial release to carbohydrate intolerance in mild diabetes mellitus. $\mathrm{J}$ Clin Invest 46: 323-325

30. Landgraf R, Landgraf-Leurs MMC, Lander T, Scholz S, Kuntz B, Albert ED (1976) HLA Haplotypes and glucose tolerance in families of patients with juvenile-onset diabetes mellitus. Lancet 2: 1084-1085

31. Barbosa J, Chavers B, Steffes M, Szalapski E, Cohen RA, Michael A, Hoogwerf B, Mauer M (1980) Muscle extracellular membrane immunofluorescence and HLA as possible markers of prediabetes. Lancet $2: 330-333$

32. Akerblom $\mathrm{H}$, Ilonen J, Mustonen T, Kiovukangas T, Herva E, Tiilikainen A, Kouvalainen K, Lautala P (1979) The use of HLA identity in the search for predisposition to juvenile-onset, insulindependent diabetes mellitus. Excerpta Medica 481: 5-6

33. Gorsuch AN, Spencer KM, Lister J, McNally JM, Dean BM, Bottazzo GF, Gudworth AG (1981) Evidence for a long prediabetic period in Type 1 (insulin-dependent) diabetes mellitus. Lancet 2: $1363-1365$

Received: 15 February 1985

and in revised form: 5 November 1985

Dr. T.J. Orchard

Department of Epidemiology

Graduate School of Public Health

University of Pittsburgh

130 DeSoto Street

Pittsburgh, PA 15261 USA 